\title{
Hybrid Carcinomas of the Salivary Glands: Report of Nine Cases with a Clinicopathologic, Immunohistochemical, and p53 Gene Alteration Analysis
}

\author{
Toshitaka Nagao, M.D., Isamu Sugano, M.D., Yasuo Ishida, M.D., Akira Asoh, Ph.D., \\ Shigeru Munakata, Ph.D., Kazuto Yamazaki, M.D., Akiyoshi Konno, M.D., Keiichi Iwaya, M.D., \\ Tohru Shimizu, M.D., Hiromi Serizawa, M.D., Yoshiro Ebihara, M.D. \\ Department of Surgical Pathology, Tokyo Medical University Hospital (TN, KI, TS, HS, YE), Tokyo, Japan; \\ Department of Surgical Pathology, Teikyo University, School of Medicine, Ichihara Hospital (IS, YI, AA, \\ SM, KY), Chiba, Japan; and Department of Otolaryngology, Chiba University, School of Medicine (AK), \\ Chiba, Japan
}

Hybrid carcinomas of the salivary gland are a recently defined and rare tumor entity, consisting of two histologically distinct types of carcinoma within the same topographic area. In this study, we examined nine such cases, which mainly arose in the parotid gland (seven cases), with an additional one each from submandibular and lacrimal glands, and analyzed their clinicopathologic profiles, including immunohistochemical features and $p 53$ gene alterations. The prevalence of hybrid carcinomas was $0.4 \%$ among the 1863 cases of parotid gland tumors in our series. The nine patients comprised five men and four women, ranging in age from 40 to 81 years (mean, $62 \mathrm{y}$ ). Tumor size ranged from 2 to $10 \mathrm{~cm}$ (mean, $4.2 \mathrm{~cm}$ ). Of the seven patients who were followed up, two were alive with disease and five were alive with no evidence of disease, although the follow-up period was short. Three cases had cervical lymph nodal metastases. The combinations of carcinoma components in our hybrid carcinomas were as follows: epithelial-myoepithelial carcinoma and basal cell adenocarcinoma in two cases, epithelial-myoepithelial carcinoma and squamous cell carcinoma in one case, salivary duct carcinoma and adenoid cystic carcinoma in two cases, myoepithelial carcinoma and salivary duct carcinoma in one, acinic cell carcinoma and salivary duct carcinoma in one, and squamous cell carcinoma and salivary duct carcinoma in two. Although the proportion

Copyright (C) 2002 by The United States and Canadian Academy of Pathology, Inc.

VOL. 15, NO. 7, P. 724, 2002 Printed in the U.S.A.

Date of acceptance: April 1, 2002.

Address reprint requests to: Toshitaka Nagao, M.D., Department of Surgical Pathology, Tokyo Medical University Hospital, 6-7-1 Nishishinjuku, Shinjuku-ku, Tokyo 160-0023, Japan; e-mail: nagao-t@tokyo-med.ac.jp; fax: 81-3-3342-2062.

DOI: 10.1097/01.MP.0000018977.18942.FD of each carcinoma component in a tumor mass varied from case to case, the minor component always represented $\geq 10 \%$ of the area. Differences in cellular composition were studied by immunohistochemistry and electron microscopy. The Ki-67-labeling index apparently differed between the two carcinoma elements in five cases. Diffusely positive p53 immunoreactivity was observed in four cases, restricted to the more aggressive component in each pair. Furthermore, p53 gene alteration analysis of these p53positive cases revealed that all and three cases demonstrated/loss of heterozygosity at p53 microsatellite loci and p53 gene point mutations, respectively, which were detected only in the p53-immunoreactive carcinoma component. Therefore, there is the possibility that such molecular-genetic events take an integral part for inducing the transformation from histologically lower to higher grade tumor during the hybrid carcinoma genesis of the salivary glands.

KEY WORDS: Hybrid carcinoma, Lacrimal gland, Parotid gland, p53, Salivary duct carcinoma, Salivary gland.

Mod Pathol 2002;15(7):724-733

Salivary gland tumors are known to have diverse histologic features, sometimes exhibiting histologic patterns observed in different tumor entities. Recently, Seifert and Donath (1) defined a new salivary gland tumor entity, characterized by containing two histologically distinct types of tumor within the same topographical area, and proposed the term hybrid tumor. Hybrid tumors are very rare neoplasms, accounting for $<0.1 \%$ of all salivary gland tumors (1). Examples of both benign (1) and malignant (1-10) hybrid tumors have been reported, the latter being referred to as hybrid carci- 
nomas $(5,7-10)$. It has been postulated that the two tumor components have an identical origin because of the consistent presence of a transitional feature between the two $(1,5)$. Because hybrid carcinomas arising in the salivary glands are rare, their clinicopathologic and immunohistochemical characteristics have not yet been well defined. Furthermore, the molecular-genetic changes involved in the pathway of transition between the two carcinoma components are also unknown.

In this study, we document the clinicopathologic and immunohistochemical findings in nine cases of hybrid carcinoma arising in the salivary glands. Additionally, we also analyzed $p 53$ gene alterations separately in each tumor element. To our knowledge, this is the first molecular-genetic assessment of hybrid carcinomas arising in the salivary glands.

\section{MATERIALS AND METHODS}

\section{Case Selection and Tissue Preparation}

We examined nine cases that fulfilled the criteria for hybrid carcinoma defined by Seifert and Donath (1). Seven cases arose in the parotid glands; these were detected among 1863 surgically resected primary parotid gland tumors appearing in the files of Chiba University Hospital and other hospitals in Japan between 1953 and 2000. One case each arose in the right submandibular and the right lacrimal gland. Several-step tissue sections were fixed in $10 \%$ buffered formalin and processed by routine histologic techniques, including periodic acidSchiff, Alcian blue, and mucicarmine. For electron microscopy, in one case, the material was fixed in $2.5 \%$ glutaraldehyde in phosphate buffer at $4^{\circ} \mathrm{C}$, postfixed in $1 \%$ osmium tetroxide, and embedded in Epon-812. Ultrathin sections were stained with lead citrate and examined in a JEM-1200EX electron microscope (JEOL, Tokyo, Japan).

\section{Immunohistochemistry}

The deparaffinized and rehydrated slides were boiled in $10 \mathrm{~mm}$ citrate buffer ( $\mathrm{pH}$ 6.0) for $10 \mathrm{~min}$ - utes in an autoclave at $121^{\circ} \mathrm{C}$. After being cooled for 30 minutes, they were incubated with the primary antibody for 1 hour at room temperature. The primary antibodies used in this study are listed in Table 1. A labeled streptavidin-biotin peroxidase method (LSAB Kit; DAKO, Glostrup, Denmark) was used for detection, employing 3,3'-diaminobenzidine as the chromogen. The sections were slightly counterstained with hematoxylin. Normal salivary gland tissue adjacent to the tumor was used as a control. A case was considered to be positive for p53 when $>10 \%$ of tumor cell nuclei showed diffuse, strong staining. The cases were regarded as positive for c-erbB-2 and epidermal growth factor receptor when intensely positive staining of the cell membrane was seen in $>10 \%$ of tumor cells. The percentage of Ki-67-positive cells was determined by counting $>1000$ tumor cells and then recorded as the Ki-67 labeling index (LI).

\section{Molecular Analysis}

DNA was carefully extracted from the paraffinembedded sections of two histologically different tumor components and normal tissues in each case by the microdissection method. The primer sequences for PCR amplification are listed in Table 2. Forward primers of TP53 locus and a variable tandem repeat (VNTR) section in p53 intron 1 were labeled with 6-FAM for loss of heterozygosity $(\mathrm{LOH})$ analysis, LOH analysis was performed with a fluorescence-based microsatellite PCR technique using an ABI PRISM 310 Genetic Analyzer (Perkin Elmer, Foster City, CA) and Gene Scan 2.01 software (Perkin Elmer). The ratios of the normal and tumor allele peak areas were compared for $\mathrm{LOH}$ assessment. A change in the ratio of $>50 \%$ indicated the loss of one allele in the carcinoma DNA (11). Mutational analysis was performed for $p 53$ exon $5-8$ by direct DNA sequencing. The DNA was sequenced with a dRhodamine Terminator Cycle Sequencing Ready Reaction Kit (Perkin Elmer) and an ABI PRISM 310 Genetic Analyzer (Perkin Elmer).

\section{TABLE 1. Antibodies Used in This Study}

\begin{tabular}{lll}
\hline \multicolumn{1}{c}{ Antigen (Antibody) } & \multicolumn{1}{c}{ Source } & Clonality \\
\hline Cytokeratin (AE1/AE3) & DAKO, Glostrup, Denmark & Monoclonal \\
Cytokeratin (CAM 5.2) & Becton Dickinson, San Jose, CA & Monoclonal \\
$\alpha$-Smooth muscle actin & Nichirei, Tokyo, Japan & Monoclonal \\
S-100 protein & DAKO & Polyclonal \\
Vimentin & DAKO & Monoclonal \\
BRST-2 (GCDFP-15) & Signet Laboratories, Dedham, MA & Monoclonal \\
CEA & Nichirei & Monoclonal \\
p53 (DO7) & Novocastra Laboratories, Newcastle, UK & Monoclonal \\
C-erbB-2 & Novocastra & Monoclonal \\
EGFR & Novocastra & Prediluted \\
Ki-67 (MIB-1) & Immunotech S.A., Marseille, France & $(1: 100)$ \\
& $(1: 20)$ & Monoclonal \\
\end{tabular}

GCDFP-15, gross cystic disease fluid protein-15; CEA, carcinoembryonic antigen; EGFR, epidermal growth factor receptor. 
TABLE 2. Sequence of the PCR Primers Used in This Study

\begin{tabular}{lll}
\hline \multicolumn{1}{c}{ Gene } & Direction & \multicolumn{1}{c}{ Sequence $\left(5^{\prime}\right.$ to ${ }^{\prime}$ ) } \\
\hline TP53 & Forward & AGGGATACTATTCAGCCCGAGGTG \\
& Reverse & ACTGCCACTCCTTGCCCATTC \\
VNTR & Forward & ACTCCAGCCTGGGCAATAAGAGCT \\
& Reverse & ACAAAACATCCCCTACCAAACAGC \\
$p 53$ exon 5 & Forward & TTCCTCTTCCTACAGTACTCC \\
& Reverse & GCCCCAGCTGCTCACCATCG \\
p53 exon 6 & Forward & TCACTGATTGCTCTTAGGTCTGGC \\
& Reverse & ACTGACAACCACCCTTAACCCC \\
$p 53$ exon 7 & Forward & TCTCCTAGGTTGGCTCTGAC \\
& Reverse & CAAGTGGCTCCTGACCTGGA \\
$p 53$ exon 8 & Forward & GCCTCTTGCTTCTCTTTCCTATCC \\
& Reverse & ATAACTGCACCCTTGGTCTCCTCC \\
\hline
\end{tabular}

VNTR, variable tandem repeats in $p 53$ intron 1.

\section{RESULTS}

The prevalence of hybrid carcinomas was $0.4 \%$ among 1863 cases of parotid gland tumors in our series. The clinicopathologic features of the hybrid carcinomas are summarized in Table 3 . The 9 patients comprised 5 men and 4 women, ranging in age from 40 to 81 years (mean, $62 \mathrm{y}$ ). Tumor size ranged from 2 to $10 \mathrm{~cm}$ (mean, $4.2 \mathrm{~cm}$ ). In terms of tumor location, most hybrid carcinomas (seven cases) arose in the parotid gland. Of the seven patients who were followed up (duration of follow-up, $4 \mathrm{mo}$ to $15 \mathrm{y}$ ), two were alive with disease and five were alive with no evidence of disease. Three cases had cervical lymph nodal metastases.

Microscopically, all cases of hybrid carcinoma showed a single tumor mass consisting of two distinct histological types with/invasion into the surrounding salivary or lacrimal gland tissue.

In Cases 1 and 2, the tumor was composed of epithelial-myoepithelial carcinoma (Fig. 1A) and the solid type of basal cell adenocarcinoma (Fig. $1 B)$, of which the proportion between the former and the latter was 70 and 30\% in Case 1 and 60 and $40 \%$ in Case 2. Case 3 had a tumor consisting of epithelial-myoepithelial carcinoma and squamous cell carcinoma (Fig. 1C), in the proportions of 60 and $40 \%$, respectively. In these three cases, the epithelial-myoepithelial carcinoma component showed a multilobular pattern of ductlike structures surrounded by clear cells. The ductlike structures consisted of cuboidal epithelial cells with dark cytoplasm. The clear cells were large and had irregular nuclei. The basal cell adenocarcinoma component was composed of solid nests of relatively monomorphic atypical basaloid cells showing an apparent peripheral palisading arrangement. No cribriform pattern with pseudocyst formation was observed. The squamous cell carcinoma component showed keratinization with cancer pearl formation; no mucinous cells could be demonstrated by periodic acid-Schiff, Alcian blue, and mucicarmine stainings.

In Cases 4 to 9, the hybrid carcinomas consisted of a combination of salivary duct carcinoma (Fig. 2A, B) and another histologically different carcinoma component, which was identified as adenoid cystic carcinoma (Fig. 2C) in Cases 4 and 5, myoepithelial carcinoma (Fig. 2D) in Case 6, acinic cell carcinoma (Fig. 2E) in Case 7, and keratinizing squamous cell carcinoma (Fig. 2F) in Cases 8 and 9. The proportion of each carcinoma component in the tumor mass varied from case to case (10 to 90\%; Táble 3).Salivary duct carcinoma was characterized by many distended, ductlike structures filled with atypical cells with eosinophilic cytoplasm and

TABLE 3. Clinicopathologic Features of Hybrid Carcinomas of the Salivary and Lacrimal Glands

\begin{tabular}{|c|c|c|c|c|c|c|c|c|c|}
\hline $\begin{array}{l}\text { Case } \\
\text { No. }\end{array}$ & $\begin{array}{c}\text { Age } \\
\text { (y) }\end{array}$ & Gender & Site & $\begin{array}{r}\text { Size } \\
(\mathrm{cm})\end{array}$ & Histology & $\begin{array}{l}\text { Proportion }^{a} \\
(\%)\end{array}$ & Therapy & Metastasis & Follow-up \\
\hline 1 & 74 & $\mathrm{~F}$ & R. parotid & 10 & $\begin{array}{l}\text { 1) EMC } \\
\text { 2) BCAC (solid type) }\end{array}$ & $\frac{70}{30}$ & $\mathrm{TP}+\mathrm{RT}$ & - & $\mathrm{NED}$ at $10 \mathrm{mo}$ \\
\hline 2 & 56 & M & L. parotid & 2 & $\begin{array}{l}\text { 1) EMC } \\
\text { 2) BCAC (solid type) }\end{array}$ & $\begin{array}{l}60 \\
40\end{array}$ & $\mathrm{SP}+\mathrm{RND}+\mathrm{RT}$ & - & $\mathrm{NED}$ at $2 \mathrm{y}, 7 \mathrm{mo}$ \\
\hline 3 & 73 & $\mathrm{~F}$ & L. parotid & 2 & $\begin{array}{l}\text { 1) EMC } \\
\text { 2) Keratinizing SCC }\end{array}$ & $\begin{array}{l}60 \\
40\end{array}$ & SP & - & NED at $4 \mathrm{y}$ \\
\hline 4 & 40 & M & R. parotid & 3 & $\begin{array}{l}\text { 1) } \mathrm{SDC}) \\
\text { 2) } \mathrm{AdCC}\end{array}$ & $\begin{array}{l}80 \\
20\end{array}$ & $\mathrm{SP}+\mathrm{RT}$ & - & NED at $15 \mathrm{y}$ \\
\hline 5 & 81 & $\mathrm{~F}$ & R. submandibular & 3 & $\begin{array}{l}\text { 1) } \mathrm{SDC} \\
\text { 2) } \mathrm{AdCC}\end{array}$ & $\begin{array}{l}80 \\
20\end{array}$ & $\mathrm{TG}+\mathrm{RND}+\mathrm{RT}$ & $\mathrm{LN}+$ & Lost \\
\hline 6 & 65 & M & R. parotid & 5 & $\begin{array}{l}\text { 1) MC (clear-cell type) } \\
\text { 2) SDC }\end{array}$ & $\begin{array}{l}90 \\
10\end{array}$ & $\mathrm{TP}+\mathrm{RND}+\mathrm{RT}$ & $\mathrm{LN}+$ & AWD at $4 \mathrm{mo}$ \\
\hline 7 & 42 & M & L. parotid & 4 & $\begin{array}{l}\text { 1) ACC (microcystic variant) } \\
\text { 2) SDC }\end{array}$ & $\begin{array}{l}70 \\
30\end{array}$ & SP & - & Lost \\
\hline 8 & 66 & M & R. parotid & 3.5 & $\begin{array}{l}\text { 1) Keratinizing SCC } \\
\text { 2) SDC }\end{array}$ & $\begin{array}{l}80 \\
20\end{array}$ & $\mathrm{TP}+\mathrm{RND}+\mathrm{RT}$ & $\mathrm{LN}+$ & AWD at $1 \mathrm{y}, 8 \mathrm{mo}$ \\
\hline 9 & 64 & $\mathrm{~F}$ & R. lacrimal & 5 & $\begin{array}{l}\text { 1) Keratinizing SCC } \\
\text { 2) SDC }\end{array}$ & $\begin{array}{l}70 \\
30\end{array}$ & Excision & - & $\mathrm{NED}$ at $7 \mathrm{mo}$ \\
\hline
\end{tabular}

F, female; R, right; EMC, epithelial-myoepithelial carcinoma; TP, total parotidectomy; RT, radiation therapy; NED, no evidence of disease; BCAC, basal cell adenocarcinoma; M, male; L, left; SP, superficial parotidectomy; RND, radical neck dissection; TG, total glandectomy; SCC, squamous cell carcinoma; SDC, salivary duct carcinoma; AdCC, adenoid cystic carcinoma; MC, myoepithlial carcinoma; AWD, alive with disease; LN, lymph node; ACC, acinic cell carcinoma.

${ }^{a}$ Approximate proportion of the area of the area of the each carcinomatous component in the tumor mass (\%). 


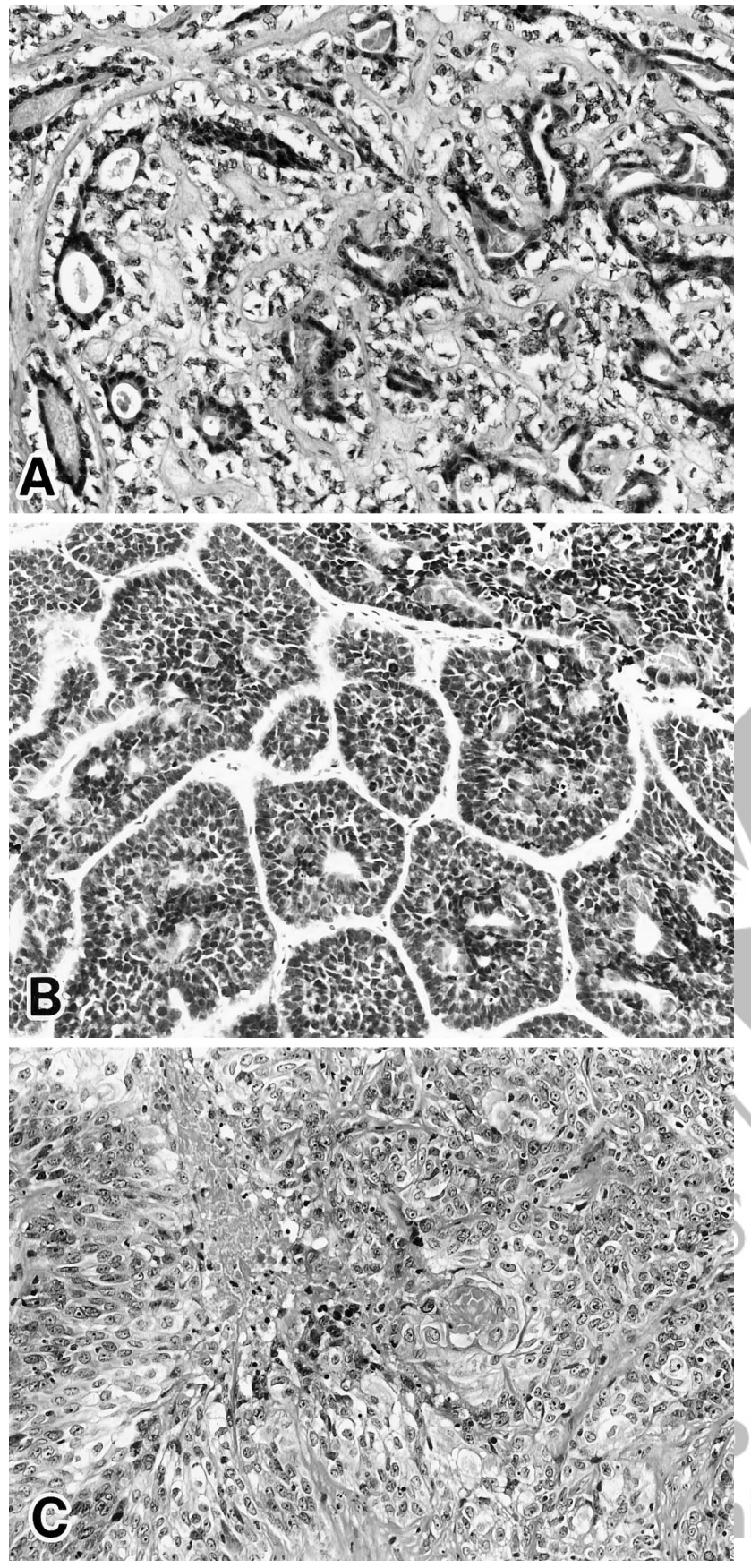

FIGURE 1. A, Case 1. Epithelial-myoepithelial carcinoma component showing a multilobular pattern with ductlike structures surrounded by clear cells. B, Case 1. Basal cell adenocarcinoma component comprising relatively monomorphic atypical basaloid cells forming solid cell nests with apparent peripheral palisading arrangement. C, Case 3. Squamous cell carcinoma component with keratinization and necrosis.

prominent nucleoli. The tumor cells showed a cribriform, papillary, or solid growth pattern. Apocrinelike metaplasia was seen when cells displayed a papillary arrangement along the dilated cystic wall. Occasionally, the central portion of the cell cluster underwent comedolike necrosis. Scirrhous growth pattern was also observed. Prominent vascular involvement was seen in Cases 5, 6, and 8. Adenoid cystic carcinoma presented with a cribriform pat- tern, in which cystlike spaces contained pale basophilic or eosinophilic basal lamina material. The tumor cells had small and angular dark nuclei and scant cytoplasm, and in Case 4 they showed frequent perineural invasion. The myoepithelial carcinoma in Case 6 was characterized by sheetlike and solid growth patterns of clear epithelioid cells. The acinic cell carcinoma in Case 7 consisted of solid tumor-cell nests showing a microcystic growth pattern with lymphoid stroma. The tumor cells had mild atypia compared with those in salivary duct carcinomas.

Although two distinct carcinoma components could be recognized in all of these cases of hybrid carcinoma, a transitional zone between them was always present (Fig. 2G). Only one of the two hybrid carcinoma components metastasized to the cervical lymph nodes in Cases 5 (salivary duct carcinoma) and 6 (myoepithelial carcinoma; Fig. 2H), and both components metastasized in Case 8 .

The results of immunohistochemical staining of these hybrid carcinomas are presented in Table 4 . In epithelial-myoepithelial carcinoma, the inner ductlike cells were intensely positive for cytokeratin (AE1/AE3, CAM 5.2), whereas the outer clear cells were immunoreactive for $\alpha$-smooth muscle actin (SMA; Fig. 3A), vimentin, and S-100 protein. On the other hand, in basal cell adenocarcinoma, cytokeratin (AE1/AE3, CAM 5.2) was diffusely positive and $\alpha$-SMA-, vimentin- and S-100 protein-positive cells tended to be located at the periphery of a solid tumor cell nest. Salivary duct carcinomas were frequently immunoreactive for cytokeratin (AE1/AE3, CAM 5.2), gross cystic disease fluid protein-15 (Fig. 3B), and carcinoembryonic antigen, whereas adenoid cystic carcinoma and myoepithelial carcinoma were negative for the latter two antigens. $\alpha$-SMA, vimentin, and S-100 protein were all positive in adenoid cystic carcinoma and myoepithelial carcinoma but negative in salivary duct carcinomas. In squamous cell carcinomas, tumor cells were negative for one of the two cytokeratin antibodies (CAM 5.2) in two of three cases. c-erbB2 was positive in two cases; one case showed immunoreactivity in both carcinoma components (Case 6) and the other in only one component (Case 9). Five cases were positive for epidermal growth factor receptor, including four cases with positivity in both carcinoma components. p53 was positive in one of the two carcinoma components (Fig. 3C) in four cases. In five cases, the Ki-67 LI apparently differed between the two carcinoma components (Fig. 3D).

Electron microscopic examination in Case 9 revealed that the salivary duct carcinoma component had glandular structures with many microvilli projecting into the lumen (Fig. 4A). In the squamous cell carcinoma, tumor cells contained abundant 

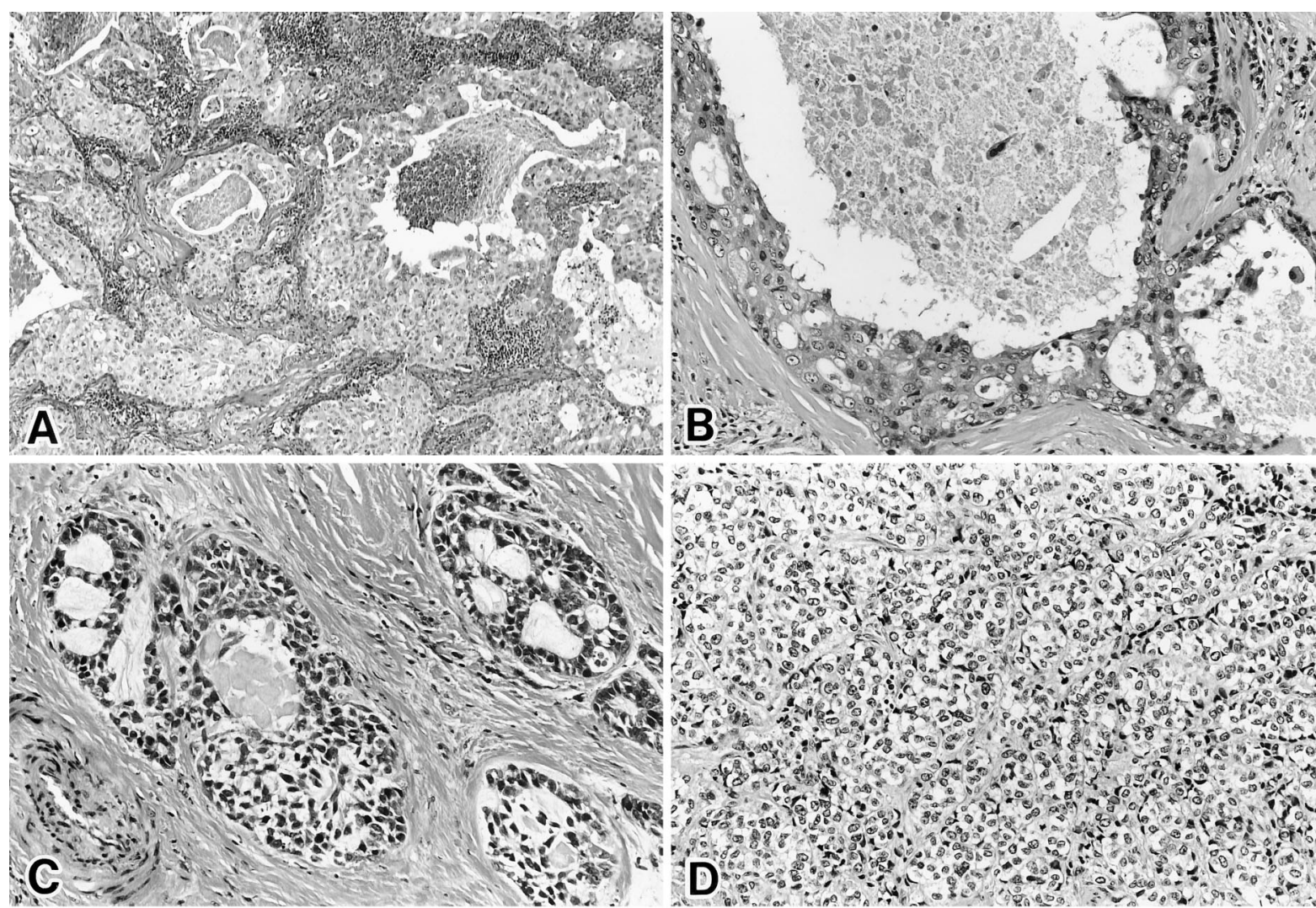

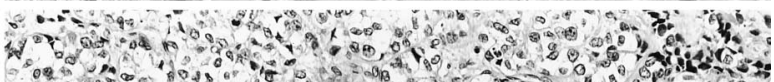
8.0.

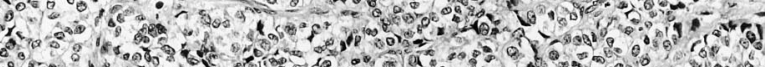

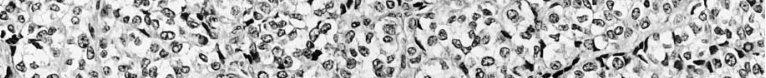

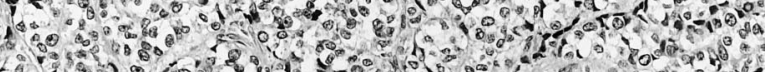

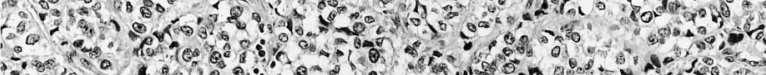
\% a

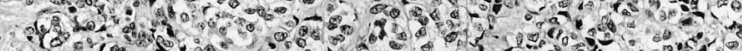

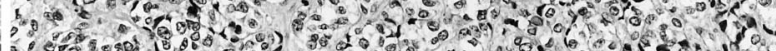

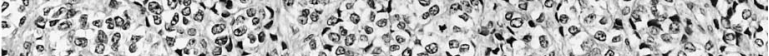
D
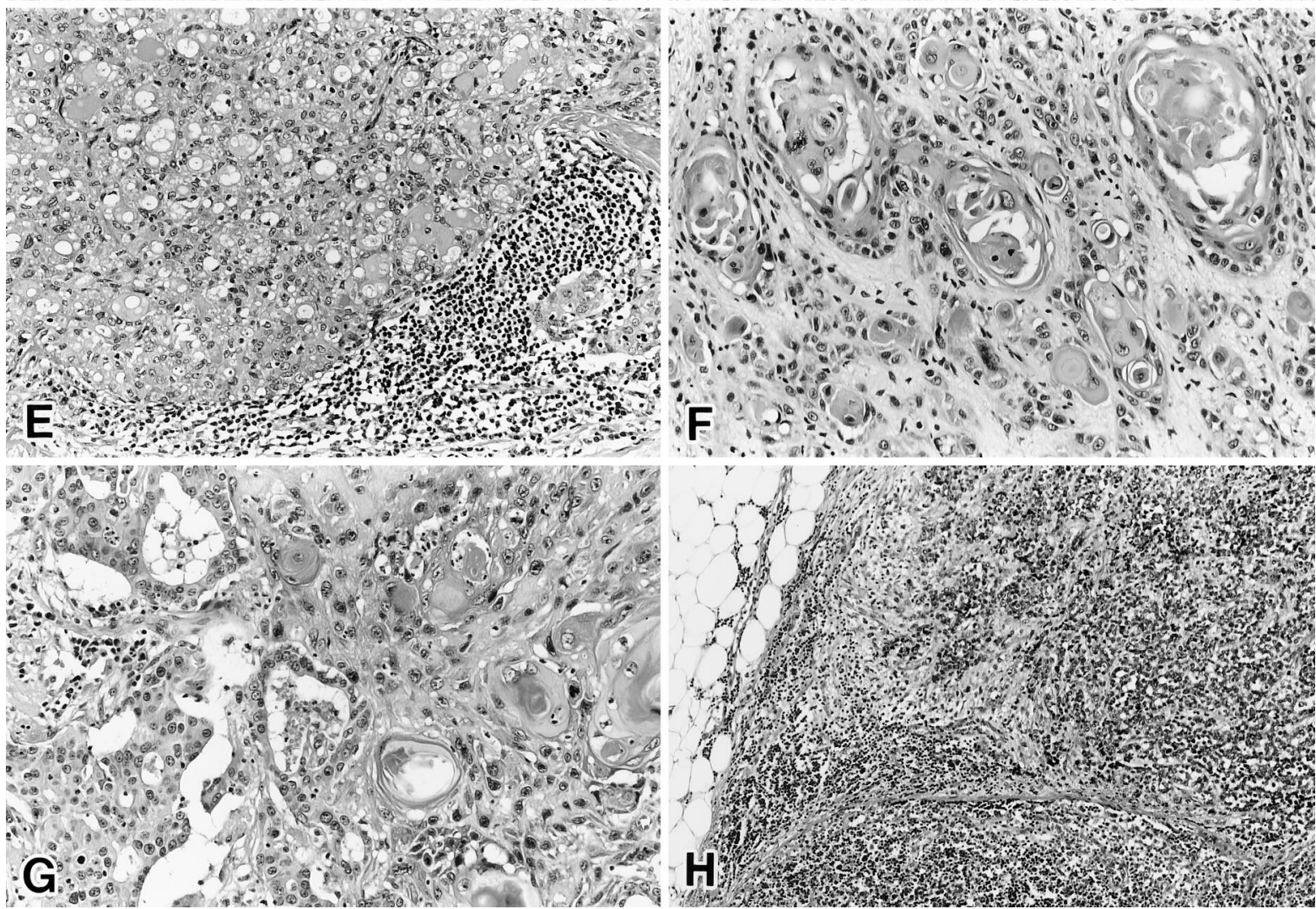

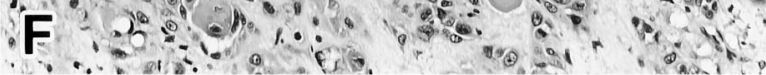

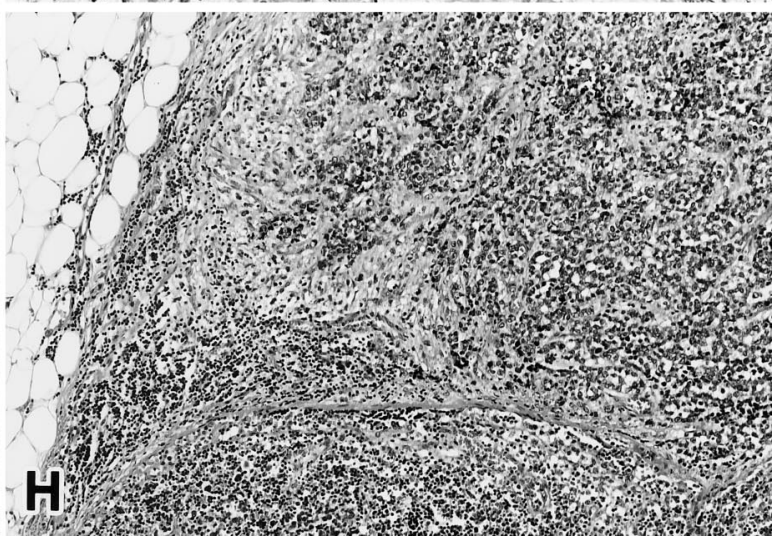

FIGURE 2. Case 9 (A) and Case 4 (B). Salivary duct carcinoma component characterized by distended ductlike structures with cribriform growth pattern and comedo-like necrosis. Carcinoma cells have eosinophilic cytoplasm and prominent nucleoli. C, Case 4. Adenoid cystic carcinoma showing cribriform pattern with cystlike spaces. Carcinoma cells have small and angular dark nuclei and scant cytoplasm. D, Case 6. The myoepithelial carcinoma component is composed of sheet and solid growth patterns of epithelioid cells exhibiting clear cytoplasm. E, Case 7. Acinic cell carcinoma component showing solid tumor-cell nests with a microcystic pattern of growth and lymphoid stroma. F, Case 8. Squamous cell carcinoma component showing scattered foci of keratinization and cancer pearl formation. G, Case 9. Salivary duct carcinoma component on the left and keratinizing squamous cell carcinoma component on the right. $\mathbf{H}$, Case 6. Myoepithelial carcinoma metastasized to the lymph node. 
TABLE 4. Results of Immunohistochemical Staining in Hybrid Carcinomas

\begin{tabular}{|c|c|c|c|c|c|c|c|c|c|c|c|c|}
\hline Case No. & Histology & AE1/AE3 & CAM 5.2 & SMA & S-100 & Vim & GCDFP-15 & CEA & c-erbB-2 & EGFR & p53 & $\begin{array}{c}\text { MIB- } \\
1(\%)\end{array}$ \\
\hline \multirow[t]{2}{*}{1} & EMC & + & + & + & + & + & ND & - & - & + & - & 10.8 \\
\hline & BCAC & + & + & + & + & + & ND & - & - & + & - & 22.2 \\
\hline \multirow[t]{2}{*}{2} & EMC & + & + & + & + & + & ND & - & - & + & - & 13.6 \\
\hline & BCAC & + & + & + & + & + & ND & - & - & + & - & 25.5 \\
\hline \multirow[t]{2}{*}{3} & EMC & + & + & + & + & + & ND & - & - & $\mathrm{F}+$ & - & 24.9 \\
\hline & SCC & + & + & - & $\mathrm{F}+$ & + & ND & - & - & $\mathrm{F}+$ & - & 55.1 \\
\hline \multirow[t]{2}{*}{4} & SDC & + & + & - & - & - & + & + & - & - & - & 32.1 \\
\hline & AdCC & + & + & + & + & + & - & - & - & - & - & 19.7 \\
\hline \multirow[t]{2}{*}{5} & SDC & + & ND & - & + & ND & - & $\mathrm{F}+$ & - & ND & + & 73.5 \\
\hline & AdCC & + & ND & + & + & ND & - & - & - & ND & - & 1.3 \\
\hline \multirow[t]{2}{*}{6} & $\mathrm{MC}$ & + & + & $\mathrm{F}+$ & + & + & - & - & + & - & - & 71.6 \\
\hline & SDC & + & + & - & - & - & + & + & + & - & + & 51.3 \\
\hline \multirow[t]{2}{*}{7} & ACC & + & + & ND & ND & ND & - & - & - & - & - & 5.2 \\
\hline & SDC & + & + & ND & ND & ND & - & - & - & - & - & 35.1 \\
\hline \multirow[t]{2}{*}{8} & SCC & + & - & ND & ND & ND & - & - & - & + & + & 35.7 \\
\hline & SDC & + & + & ND & ND & ND & + & + & - & + & - & 23.7 \\
\hline \multirow[t]{2}{*}{9} & SCC & + & - & ND & ND & ND & - & - & - & + & + & 50.9 \\
\hline & SDC & + & + & ND & ND & ND & + & + & + & - & - & 12.1 \\
\hline
\end{tabular}

AE1/AE3, cytokeratin (AE1/AE3); CAM 5.2, cytokeratin (CAM 5.2); SMA: $\alpha$-smooth muscle actin; S-100, S-100 protein; Vim, vimentin; GCDFP-15, gross cystic disease fluid protein-15; CEA, carcinoembryonic antigen; EGFR, epidermal growth factor receptor; EMC, epithelial-myoepithelial carcinoma; ND, not done; BCAC, basal cell adenocarcinoma; SCC, squamous cell carcinoma; AdCC, adenoid cystic carcinoma; SDC, salivary duct carcinoma; MC, myoepithelial carcinoma; ACC, acinic cell carcinoma.

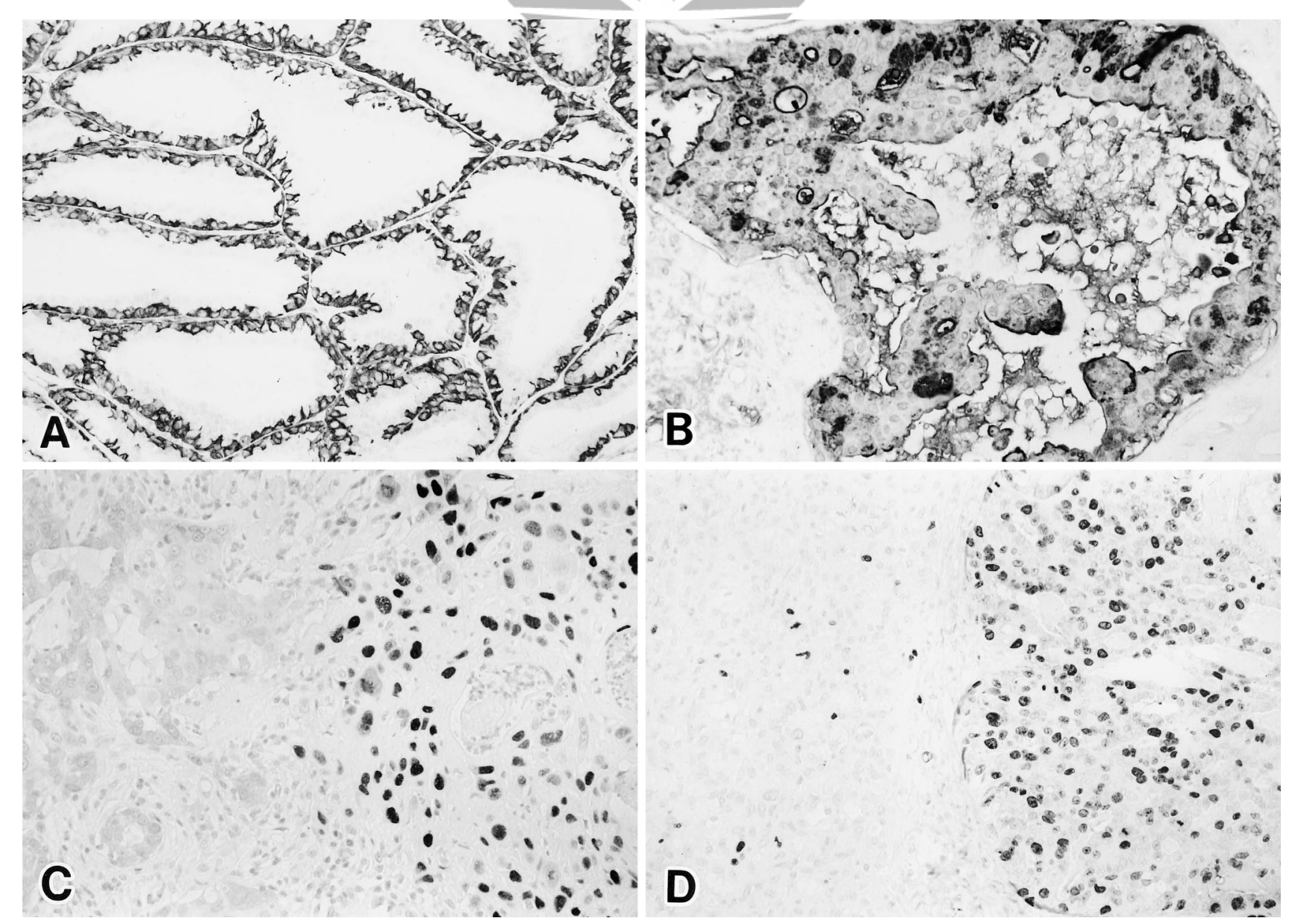

FIGURE 3. Immunohistochemistry of hybrid carcinomas. A, Case 2. Epithelial-myoepithelial carcinoma component. The outer clear cells are intensely immunoreactive for $\alpha$-smooth muscle actin. B, Case 8. Salivary duct carcinoma component. Gross cystic disease fluid protein-15 is strongly positive in the tumor cells as well as in the luminal contents. C, Case 9. p53 is strongly expressed in the squamous cell carcinoma component on the right, whereas the salivary duct carcinoma component on the left is completely negative. D, Case 7. Apparently different Ki-67 (MIB-1)

immunoreactivity can be noted between the acinic cell carcinoma component on the left (labeling index, $5.2 \%$ ) and the salivary duct carcinoma component on the right (labeling index, 35.1\%). 
tonofilament bundles and were connected by many desmosomes (Fig. 4B).

p53 gene alteration analysis was performed in Cases 5, 6, 8, and 9, which presented diffusely positive p53 immunoreactivity (Table 5). All of these cases had LOH at p53 microsatellite loci (TP53 and VNTR in $p 53$ intron 1), which was detected only in the p53-immunoreactive carcinoma component. For the analysis of $p 53$ mutations, we amplified and sequenced four highly conserved gene regions, corresponding to exons 5 through 8 . Three cases dem-

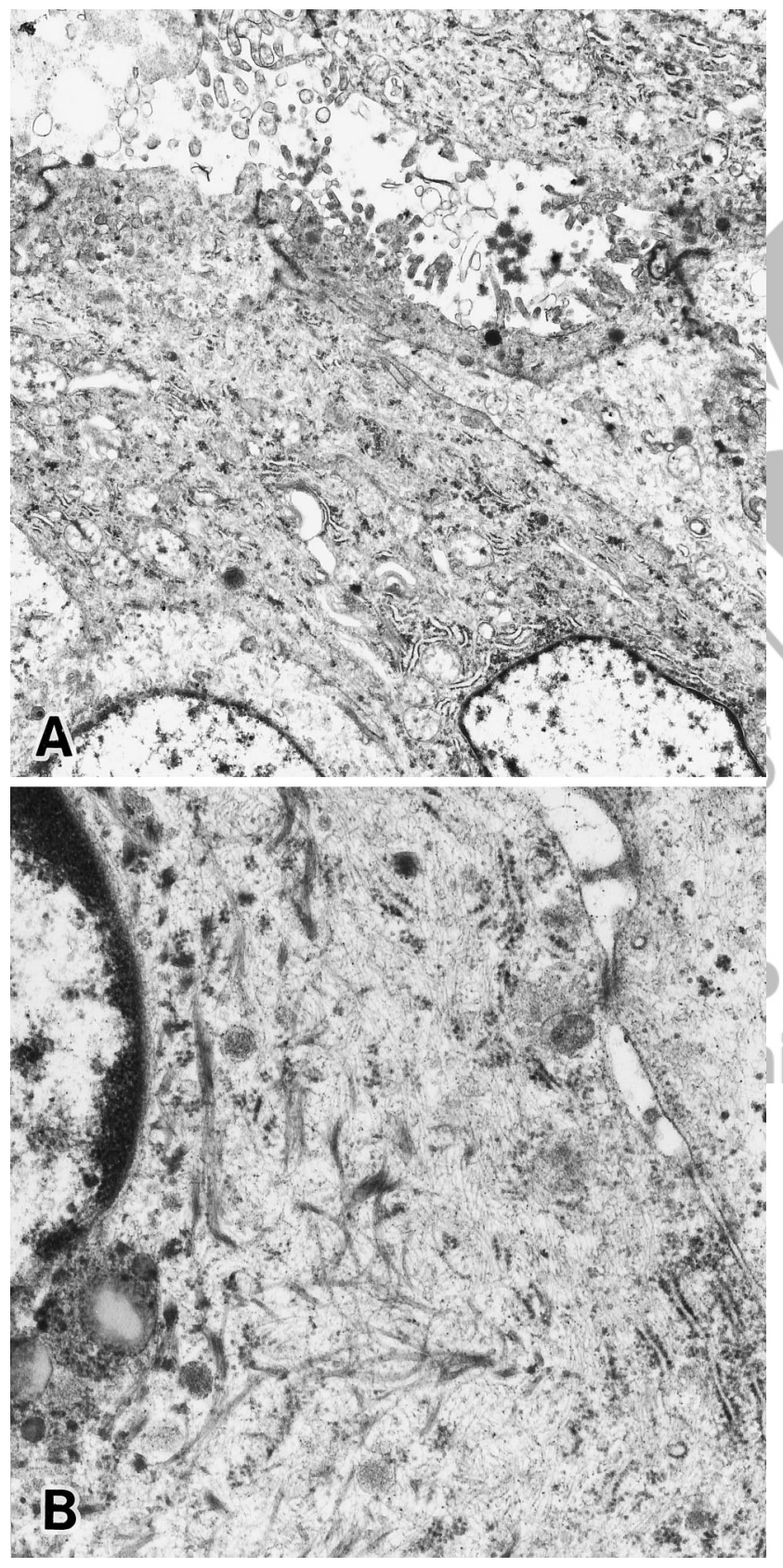

FIGURE 4. Ultrastructural features of hybrid carcinoma. Case 9. A, salivary duct carcinoma component showing glandular structures with many microvilli projecting into the lumen. B, squamous cell carcinoma component containing abundant tonofilament bundles and many desmosomes. onstrated point mutations confined to one of the two carcinoma components: CGG (Arg) to GGG (Gly) transition at codon 282 on exon 8 in Case 5 (Fig. 5), GGC (Gly) to AGC (Ser) transition at codon 245 on exon 7 in Case 6, and CGA (Arg) to GGA (Gly) transition at codon 196 on exon 6 in Case 9. No p53 mutations were found in Case 8.

\section{DISCUSSION}

Hybrid carcinomas of the salivary gland are rare (1) and, to our knowledge, only 14 such cases have been reported, as presented in Table 6 (1-10). Various carcinoma combinations have been described in hybrid carcinomas; salivary duct carcinoma, epithelial-myoepithelial carcinoma, and adenoid cystic carcinoma are frequently involved, as in our series (Tables 3 and 6) (1-10). Although little prognostic information is available, several investigators have suggested that the aggressiveness of hybrid carcinomas is determined by the histologically higher grade component $(1,5,7,8,10)$. In 2 of the 3 cases with cervical nodal metastasis in our series, only one component of the hybrid carcinoma metastasized to the neck lymph nodes. It would appear that management of hybrid carcinomas should be targeted at the higher grade tumor component, but this issue requires further confirmation in much larger series with longer follow-up.

The concept of hybrid carcinoma is subject to some confusion, and careful diagnosis is required. Several salivary gland tumor entities that exhibit two or more different morphologies should be ruled out before a diagnosis of hybrid carcinoma is made $(1,12)$. These entities include collision tumors $(1$, 12), synchronous and multiple tumors (13), carcinomas with metaplastic change (14-16), dedifferentiated carcinomas (17-19), sarcomatoid salivary duct carcinoma (20), adenosquamous carcinoma $(21,22)$, and malignant mixed tumors (22). All of our cases were defined as hybrid carcinomas because there were two distinct and separable carcinomas in the same topographic area, producing a single tumor mass. The presence of a transitional zone between the two carcinoma components, suggesting their identical origin, differentiates our cases from collision tumors, which are a meeting of two carcinomas arising from independent topographical sites $(1,12)$, and from synchronous and multiple tumors (13). It has been reported that epithelial-myoepithelial carcinoma $(14,15)$ and salivary duct carcinoma $(3,16)$ may exhibit focal squamous metaplasia. Obviously, such carcinomas with metaplastic change should not be considered to contain two different carcinoma types. Some salivary gland carcinomas, such as acinic cell carcinoma (17), adenoid cystic carcinoma (18), and epi- 
TABLE 5. p53 Alterations Detected by Immunohistochemistry (IHC), Loss of Heterozygosity (LOH) Analysis, and Direct DNA Sequencing in Hybrid Carcinomas

\begin{tabular}{|c|c|c|c|c|c|}
\hline \multirow{2}{*}{$\begin{array}{c}\text { Case } \\
\text { No. }\end{array}$} & \multirow{2}{*}{ Histology } & \multirow{2}{*}{ IHC } & \multicolumn{2}{|c|}{$\mathrm{LOH}$} & \multirow{2}{*}{ Mutation (Exons 5-8) } \\
\hline & & & TP53 & VNTR & \\
\hline \multirow[t]{2}{*}{5} & SDC & + & - & + & Codon 282, CGG (Arg) to GGG (Gly) \\
\hline & AdCC & - & - & - & - \\
\hline \multirow[t]{2}{*}{6} & MC & - & - & - & - \\
\hline & SDC & + & - & + & Codon 245, GGC (Gly) to AGC (Ser) \\
\hline \multirow[t]{2}{*}{8} & SCC & + & + & + & - \\
\hline & SDC & - & - & - & - \\
\hline \multirow[t]{2}{*}{9} & SCC & + & - & + & Codon 196, CGA (Arg) to GGA (Gly) \\
\hline & SDC & - & - & - & - \\
\hline
\end{tabular}

IHC, immunohistochemistry; LOH, loss of heterozygosity; VNTR, variable tandem repeats in $p 53$ intron 1; SDC, salivary duct carcinoma; AdCC, adenoid cystic carcinoma; MC, myoepithelial carcinoma; SCC, squamous cell carcinoma; +, positive; -, negative.

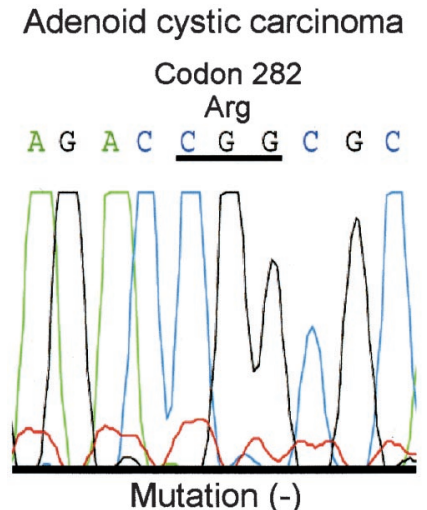

Salivary duct carcinoma

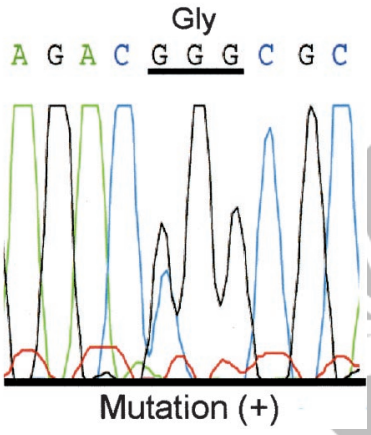

FIGURE 5. Direct sequencing analysis of p53 exon 8 in Case 5. Salivary duct carcinoma component showing CGG to GGG transition in codon 282 results in an Arg substitution for Gly, whereas no mutations are found in the adenoid cystic carcinoma component. thelial-myoepithelial carcinoma (19), may rarely contain a dedifferentiated carcinoma component with aggressive growth. In contrast to the dedifferentiated element, which may be either undifferentiated carcinoma or poorly differentiated adenocarcinoma, hybrid carcinomas are composed of two forms of carcinoma that fall into exactly defined tumor categories. Sarcomatoid salivary duct carcinoma is a composite of common-type salivary duct carcinoma and sarcomatoid carcinoma without any noticeable squamous differentiation, a feature differing from that seen in our Cases 8 and 9 (20). Adenosquamous carcinoma should also be differentiated from our Cases 8 and 9. The adenocarcinomatous element in our cases showed certain features specific for salivary duct carcinoma, such as proliferation of pleomorphic carcinoma cells with eosinophilic cytoplasm and prominent nucleoli, exhibiting cribriform and solid growth patterns accompanied by comedo necrosis. In any case, the occurrence of adenosquamous carcinoma in the salivary or lacrimal gland is still a matter of controversy $(21,22)$. Malignant mixed tumors include three distinct pathologic entities: carcinoma ex mixed tumor, carcinosarcoma, and metastasizing mixed tumor (22). Unlike the malignant mixed tu- mors, hybrid carcinomas are composed of two different malignant epithelial tumor elements.

Some controversial issues regarding the criteria for hybrid carcinomas have been raised. Because shared foci of phenotypic differentiation may be seen within salivary tumors, Gnepp et al. (23) proposed that in hybrid carcinomas, each element would differentiate toward distinctly different salivary elements: for example, excretory duct versus acini or excretory duct versus intercalated duct. Grenko et al. (24) have described three adenoid cystic carcinomas and two epithelial-myoepithelial carcinomas that focally shared both histological features. They suggested that these two entities shared common differentiation pathways and did not categorize these examples as hybrid carcinomas. Additionally, they stated that only two tumor types, adenosquamous carcinoma and carcinosarcoma, should be included when classifying salivary gland tumors as hybrid carcinomas. On the other hand, Seifert and Donath (1) and Croitoru et al. (7) did not limit the cellular phenotypes constituting hybrid tumors. Chetty (25) suggested that completely divergent differentiation may lead to the appearance of two distinct tumor entities (hybrid tumors), whereas incomplete divergence may lead to tumors harboring overlapping histological features. Our Cases 1 and 2, which were composed of epithelial-myoepithelial carcinoma and basal cell adenocarcinoma, are the most open to discussion concerning their classification, because both of these two carcinoma components had similar cellular composition (ductal and myoepithelial cells) as revealed by immunohistochemical examination. In these cases, however, each carcinoma component occupied $\geq 30 \%$ of the tumor mass and could be separated from the other component. Moreover, cell proliferative activity was distinctly different between the two components. These two cases should thus be considered as hybrid carcinomas.

In this study, the cellular composition of the two tumor entities in each of our cases of hybrid carcinoma was confirmed by using immunohistochemical stains and electron microscopic examination. 
TABLE 6. List of Hybrid Carcinoma of the Salivary Glands Reported in the Literature

\begin{tabular}{|c|c|c|c|c|c|c|c|c|c|}
\hline $\begin{array}{l}\text { Case } \\
\text { No. }\end{array}$ & References & Year & $\begin{array}{l}\text { No. of } \\
\text { Cases }\end{array}$ & Age (y) & Gender & Site & Size $(\mathrm{cm})$ & Histology & Follow-Up \\
\hline 1 & Seifert and Donath & 1996 & 2 & 53 & M & R. parotid & $6 \times 3 \times 2$ & ACC and SDC & - \\
\hline 2 & & & & 67 & $\mathrm{~F}$ & L. palate & - & EMC and AdCC & - \\
\hline 3 & Ellis et al. & 1991 & 1 & - & - & R. parotid & 2.5 & EMC, AdCC, and BCAC & - \\
\hline 4 & Delgado et al. & 1993 & 1 & - & - & - & - & SDC and MC & - \\
\hline 5 & Ballestin et al. & 1996 & 1 & 67 & $\mathrm{~F}$ & L. parotid & 5.5 & ACC and MEC & $\mathrm{NED}$ at 1 y $6 \mathrm{mo}$ \\
\hline 6 & Kamio et al. & 1997 & 1 & 51 & M & R. palate & $4.5 \times 3$ & AdCC and SDC & Died at 1 y $7 \mathrm{mo}$ \\
\hline 7 & Simpson & 1997 & 1 & 62 & $\mathrm{~F}$ & Parotid & 3 & EMC and AdCC & $\mathrm{NED}$ at 1 y $8 \mathrm{mo}$ \\
\hline 8 & Croitoru et al. & 1999 & 4 & 53 & M & L. parotid & $6 \times 4.5 \times 3.5$ & AdCC and MEC & NED \\
\hline 9 & & & & 71 & M & R. parotid & 2.9 & AdCC and EMC & NED \\
\hline 10 & & & & 28 & M & L. parotid & $2.5 \times 2$ & EMC and SDC & AWD \\
\hline 11 & & & & 51 & M & L. palate & $3.5 \times 3$ & AdCC and SDC & AWD \\
\hline 12 & Snyder and Paulino & 1999 & 1 & 36 & $\mathrm{~F}$ & R. submandibular & $3.5 \times 2.5 \times 2$ & SDC and AdCC & AWD \\
\hline 13 & Zardawi & 2000 & 1 & 78 & $\mathrm{~F}$ & R. parotid & $4.5 \times 4 \times 3$ & PLGA, SDC, AdCC and ACC & - \\
\hline 14 & Chetty et al. & 2000 & 1 & 58 & M & Parotid & 2.5 & EMC and MEC & - \\
\hline
\end{tabular}

M, male; R, right; ACC, acinic cell carcinoma; SDC, salivary duct carcinoma; F, female; L, left; EMC, epithelial—myoepithelial carcinoma; AdCC, adenoid cystic carcinoma; BCAC, basal cell adenocarcinoma; MC, myoepithelial carcinoma; MEC, mucoepidermoid carcinoma; PLGA, polymorphous low-grade adenocarcinoma; NED, no evidence of disease; AWD, alive with disease.

Epithelial-myoepithelial carcinoma (14), basal cell adenocarcinoma (26), and adenoid cystic carcinoma (27) all exhibited bicellular differentiation into ductal cells and myoepithelial cells, but the distribution pattern of these cells in the tumor cell nests was somewhat different among the tumor types. Both salivary duct carcinoma $(1,16)$ and squamous cell carcinoma consisted of purely epithelial elements with different expression patterns of cytokeratin depending on the molecular weight, whereas myoepithelial carcinoma (28) showed myoepithelial phenotypes. The high expression of gross cystic disease fluid protein-15 and carcinoembryonic antigen is also compatible with salivary duct carcinoma (16).

The development and progression of cancer are thought to be regulated by the expression of various oncogenes and tumor suppressor genes, and this has been demonstrated for salivary gland tumors (29-33). We examined the expression of oncogenes (c-erbB2 and EGFR), a tumor suppressor gene (p53), and a cell proliferation marker (Ki-67). Of these, significant findings were noted for the expression of p53 and Ki-67, which distinctively differed between the two carcinoma components in four and five cases, respectively. In these cases, aberrations of the p53 gene coincided with p53 protein overexpression were limited to the histologically higher grade component in each pair-salivary duct carcinoma but not adenoid cystic carcinoma or myoepithelial carcinoma, and squamous cell carcinoma but not salivary duct carcinoma. In salivary gland carcinomas, p53 protein overexpression and $p 53$ gene mutations have been implicated in an tumor progression $(5,18,33)$. Therefore, there is the possibility that such molecular-genetic events take an integral part for inducing the transformation from histologically lower to higher grade tumor during the hybrid carcinoma genesis of the salivary glands.
Acknowledgments: The authors thank Mr. Kenichi Hasegawa and Mr. Atsufumi Ohba, Department of Surgical Pathology, Teikyo University, School of Medicine, Ichihara Hospital, Japan, for the excellent photographs.

\section{REFERENCES}

1. Seifert G, Donath K. Hybrid tumors of salivary glands: definition and classification of five rare cases. Eur J Cancer B Oral Oncol 1996;32B:251-9.

2. Ellis GL, Auclair PL, Gnepp DR, editors. Surgical pathology of the salivary glands. Philadelphia: Saunders; 1991. p. 455-88.

3. Delgado R, Vuitch F, Aldores-Saavedra J. Salivary duct carcinoma. Cancer 1993;72:1503-12.

4. Ballestin C, Lopez-Carreira M, Lopez JI. Combined acinic cell mucoepidermoid carcinoma of the parotid gland: report of a case with immunohistochemical study. APMIS 1996;104: 99-102.

5. Kamio N, Tanaka Y, Mukai M, Ikeda E, Kuramochi S, Fujii M, et al. A hybrid carcinoma: adenoid cystic carcinoma and salivary duct carcinoma of the salivary gland: an immunohistochemical study. Virchows Arch 1997;430:495-500.

6. Simpson PR. Pitfalls in salivary gland pathology: hybrid epithelial myoepithelial carcinoma and adenoid cystic carcinoma [abstract 067]. Pathol Res Pract 1997;193:342.

7. Croitoru CM, Suarez PA, Luna MA. Hybrid carcinomas of salivary glands: report of 4 cases and review of the literature. Arch Pathol Lab Med 1999;123:698-702.

8. Snyder ML, Paulino AF. Hybrid carcinoma of the salivary gland: salivary duct adenocarcinoma adenoid cystic carcinoma. Histopathology 1999;35:380-3.

9. Zardawi IM. Hybrid carcinoma of the salivary gland. Histopathology 2000;37:283-4.

10. Chetty R, Medley P, Essa A. Hybrid carcinomas of salivary glands. Arch Pathol Lab Med 2000;124:494-6.

11. Cawkwell L, Bell SM, Lewis FA, Dixon MF, Taylor GR, Quirke P. Rapid detection of allele loss in colorectal tumours using microsatellites and fluorescent DNA technology. Br J Cancer 1993;67:1262-7.

12. Seifert G, Donath K. Multiple tumours of the salivary glands: terminology and nomenclature. Eur J Cancer B Oral Oncol 1996;32B:3-7.

13. Gnepp DR, Schroeder W, Heffner D. Synchronous tumors arising in a single major salivary gland. Cancer 1989;63:1219-24. 
14. Fonseca I, Soares J. Epithelial-myoepithelial carcinoma of the salivary glands. a study of 22 cases. Virchows Arch A Pathol Anat Histopathol 1993;422:389-96.

15. Cho KJ, el-Naggar AK, Ordonez NG, Luna MA, Austin J, Batsakis JG. Epithelial-myoepithelial carcinoma of salivary glands: a clinicopathologic, DNA flow cytometric, and immunohistochemical study of Ki-67 and HER-2/neu oncogene. Am J Clin Pathol 1995;103:432-7.

16. Lewis JE, McKinney BC, Weiland LH, Ferreiro JA, Olsen KD. Salivary duct carcinoma: clinicopathologic and immunohistochemical review of 26 cases. Cancer 1996;77:223-30.

17. Stanley RJ, Weiland LH, Olsen KD, Pearson BW. Dedifferentiated acinic cell (acinous) carcinoma of the parotid gland. Otolaryngol Head Neck Surg 1988;98:155-61.

18. Cheuk W, Chan JK, Ngan RK. Dedifferentiation in adenoid cystic carcinoma of salivary gland: an uncommon complication associated with an accelerated clinical course. Am J Surg Pathol 1999;23:465-72.

19. Alos L, Carrillo R, Ramos J, Baez JM, Mallofre C, Fernandez PL, et al. High-grade carcinoma component in epithelialmyoepithelial carcinoma of salivary glands clinicopathological, immunohistochemical and flow-cytometric study of three cases. Virchows Arch 1999;434:291-9.

20. Henley JD, Seo IS, Dayan D, Gnepp DR. Sarcomatoid salivary duct carcinoma of the parotid gland. Hum Pathol 2000;31:208-13.

21. Seifert G, Sobin L. Histological typing of salivary gland tumors (World Health Organization). 2nd ed. New York: Springer-Verlag; 1991.

22. Ellis GL, Auclair PL. Tumors of the salivary glands. In: Atlas of tumor pathology. Washington DC: Armed Forces Institute of Pathology; 1996.

23. Gnepp DR, Brandwein MS, Henley JD. Salivary and lacrimal glands. In: Gnepp DR, editor. Diagnostic surgical pathology of the head and neck. Philadelphia: Saunders; 2001.

24. Grenko RT, Abendroth CS, Davis AT, Levin RJ, Dardick I. Hybrid tumors or salivary gland tumors sharing common differentiation pathways? Reexamining adenoid cystic and epithelial-myoepithelial carcinomas. Oral Surg Oral Med Oral Pathol Oral Radiol Endod 1998;86:188-95.

25. Chetty R. Intercalated duct hyperplasia: possible relationship to epithelial-myoepithelial carcinoma and hybrid tumours of salivary gland. Histopathology 2000;37:260-3.

26. Williams SB, Ellis GL, Auclair PL. Immunohistochemical analysis of basal cell adenocarcinoma. Oral Surg Oral Med Oral Pathol Oral Radiol Endod 1993;75:64-9.

27. Chen JC, Gnepp DR, Bedrossian CW. Adenoid cystic carcinoma of the salivary glands: an immunohistochemical analysis. Oral Surg Oral Med Oral Pathol Oral Radiol Endod 1988;65:316-26.

28. Nagao T, Sugano I, Ishida Y, Tajima Y, Matsuzaki O, Konno A, et al. Salivary gland malignant myoepithelioma: a clinicopathologic and immunohistochemical study of ten cases. Cancer 1998;83:1292-9.

29. Gallo O, Franchi A, Bianchi S, Boddi V, Giannelli E, Alajmo E. p53 oncoprotein expression in parotid gland carcinoma is associated with clinical outcome. Cancer 1995;75:2037-44.

30. Felix A, El-Naggar AK, Press MF, Ordonez NG, Fonseca I, Tucker SL, et al. Prognostic significance of biomarkers (cerbB-2, p53, proliferating cell nuclear antigen, and DNA content) in salivary duct carcinoma. Hum Pathol 1996;27: 561-6.

31. Kamio N. Coexpression of p53 and c-erbB-2 proteins is associated with histological type, tumour stage, and cell proliferation in malignant salivary gland tumors. Virchows Arch 1996;428:75-83.

32. Nagao T, Sugano I, Ishida Y, Hasegawa M, Matsuzaki O, Konno A, et al. Basal cell adenocarcinoma of the salivary glands: comparison with basal cell adenoma through assessment of cell proliferation, apoptosis, and expression of p53 and $b c l$-2. Cancer 1998;82:439-47.

33. Yamamoto Y, Wistuba II, Kishimoto Y, Virmani AK, Vuitch F, Albores-Saavedra J, et al. DNA analysis at p53 locus in adenoid cystic carcinoma: comparison of molecular study and p53 immunostaining. Pathol Int 1998;48:273-80.

\section{WILLIAMS \& WILKINS}

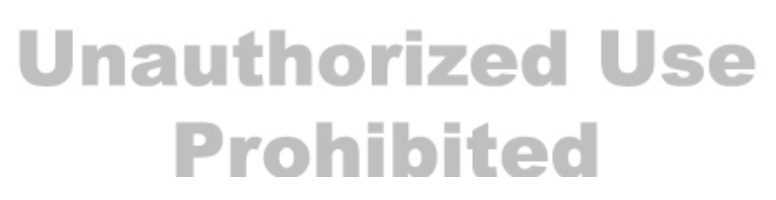

